\title{
PROSES AUTOREGRESSIVE CONDITIONAL HETEROSCEDASTICITY DENGAN DUGAAN VARIANSI INFLASI INDONESIA
}

\author{
Rianiati Monica, Suyono, dan Vera Maya Santi \\ Jurusan Matematika FMIPA UNJ
}

\begin{abstract}
Abstrak
Model-model runtun waktu konvensional, seperti model-model ARIMA, mengasumsikan bahwa variansi dari galat adalah konstan. Namun, pada kenyataannya dalam data keuangan, contohnya data inflasi, variansi galatnya berubah dari waktu ke waktu. Fenomena tersebut disebut sebagai heteroskedastisitas. Model autoregressive conditional heteroscedasticity (ARCH) seperti yang diperkenalkan oleh Engle (1982) mengakomodasikan fenomena ini. Model ARCH adalah model variansi dari suatu runtun waktu. Tujuan dari penulisan ini adalah untuk memperkenalkan model autoregressive conditional heteroscedasticity (ARCH). Teori ARCH kemudian diaplikasikan untuk menganalisis data inflasi Indonesia mulai dari Januari 2003 sampai Nopember 2015. Data diperoleh dari situs Bank Indonesia.
\end{abstract}

Kata kunci: ARIMA, heteroskedastisitas, ARCH, inflasi.

\section{Pendahuluan}

A. Latar Belakang

Autoregresi adalah suatu model yang dikembangkan untuk menganalisis data runtun waktu (time series). Pada awalnya model yang biasa digunakan untuk memodelkan suatu data runtun waktu adalah model ARIMA (Autoregressive Integrated Moving Average). Model ini mengasumsikan bahwa nilai variansi galat dari data runtun waktu adalah konstan (bersifat homokedastisitas). Namun pada kenyataannya, banyak ditemukan data runtun waktu yang memiliki masalah variansi galat tidak konstan, terutama pada data runtun waktu finansial, kondisi ini dinamakan heteroskedastisitas. Heteroskedastisitas disebabkan oleh volatilitas data yang tinggi, dimana adanya fluktuasi yang cukup tajam pada data di periode waktu tertentu namun stabil pada periode waktu yang lain. Masalah ini menyebabkan model ARIMA tidak lagi sesuai digunakan untuk memodelkan pergerakannya, karena melanggar asumsi variansi konstan.

Diperlukan suatu model baru yang tepat untuk mengalisis data runtun waktu yang bersifat heteroskedastisitas. Salah satu model runtun waktu yang digunakan untuk data yang bersifat heteroskedastisitas adalah model Autoregressive Conditional Heteroscedasticity (ARCH) (Engle, 1982). Kelebihan penggunaan model $A R C H$ dibandingkan model runtun waktu yang lain yaitu model ini mampu menduga variansi bersyarat melalui data galat pada model rataan. Sehingga sifat heteroskedastisitas pada data tidak lagi menjadi masalah, melainkan dapat menjadi informasi tambahan untuk memperoleh model yang lebih tepat. Salah satu contoh data runtun waktu yang bersifat heteroskedastisitas adalah data tingkat inflasi Indonesia, jadi model $A R C H$ akan lebih tepat jika diaplikasikan dalam memodelkan pergerakan variansinya yang tidak konstan.

\section{B. Perumusan Masalah}

1. Bagaimana pembentukan model variansi dari data runtun waktu yang bersifat heteroskedastisitas?

2. Bagaimana model variansi tingkat inflasi Indonesia?

\section{Pembatasan Masalah}

1. Pembahasan dalam skripsi ini dibatasi pada proses runtun waktu $A R C H(p)$ dengan orde $p$ hanya sampai orde pertama.

2. Analisis pada tingkat inflasi Indonesia hanya sampai pembentukkan model variansinya saja. 


\section{Landasan Teori \\ A. Runtun Waktu}

Suatu runtun waktu (time series) adalah himpunan observasi berurut yang dikumpulkan menurut urutan waktu dalam suatu rentang waktu tertentu. Makridakis (1999) mengungkapkan bahwa langkah penting dalam memilih suatu metode runtun waktu yang tepat adalah dengan mempertimbangkan jenis pola datanya. Pola data dapat dibedakan menjadi empat, yaitu:

1. Pola Data Horizontal: terjadi saat data observasi berfluktuasi di sekitar suatu nilai konstan atau rataan yang membentuk garis horizontal.

2. Pola Data Trend: terjadi saat data observasi mengalami kecenderungan naik atau turun selama periode jangka panjang.

3. Pola Data Musiman: terjadi saat suatu deret data dipengaruhi oleh faktor musiman.

4. Pola Data Siklis: terjadi saat deret data dipengaruhi oleh fluktuasi ekonomi jangka panjang seperti yang berhubungan dengan siklus bisnis.

\section{B. Proses Stokastik}

Proses stokastik adalah koleksi peubah acak $\left\{Z_{t}, t \in T\right\}$ yang didefinisikan pada ruang probabilitas $(\Omega, F, P)$, dimana $T$ menunjukkan suatu himpunan yang beranggotakan titik-titik waktu. Analisis runtun waktu merupakan realisasi dari proses stokastik. Beberapa sifat-sifat dari proses stokastik antara lain:

1. Nilai rataan dari prosesnya pada keseluruhan waktu adalah: $\mu_{t}=E\left(Z_{t}\right)$.

2. Fungsi autokovariansi antara $Z_{t}$ dan $Z_{s}$ adalah: $\gamma_{t, s}=\operatorname{Cov}\left(Z_{t}, Z_{s}\right)=E\left(\left(Z_{t}-\mu_{t}\right)\left(Z_{s}\right.\right.$ $\left.\left.\mu_{s}\right)\right)=E\left(Z_{t} Z_{s}\right)-\mu_{t} \mu_{s}$.

3. Fungsi autokorelasi antara $Z_{t}$ dan $Z_{s}$ adalah: $\rho_{t, s}=\operatorname{Corr}\left(Z_{t}, Z_{s}\right)=\frac{\gamma_{t, s}}{\sqrt{\gamma_{t, t} \gamma_{s, s}}}$.

4. Fungsi autokorelasi parsial antara $Z_{t}$ dan $Z_{s}$ adalah:

$$
\phi_{k k}=\operatorname{Corr}\left(Z_{t}, Z_{t+k} \mid Z_{t+1}, \cdots, Z_{t+k-1}\right)=\frac{\left|\begin{array}{cccccc}
1 & \rho_{1} & \rho_{2} & \cdots & \rho_{k-2} & \rho_{1} \\
\rho_{1} & 1 & \rho_{1} & \cdots & \rho_{k-3} & \rho_{2} \\
\vdots & \vdots & \vdots & \ddots & \vdots & \vdots \\
\rho_{k-1} & \rho_{k-2} & \rho_{k-3} & \cdots & \rho_{1} & \rho_{k}
\end{array}\right|}{\left|\begin{array}{cccccc}
1 & \rho_{1} & \rho_{2} & \cdots & \rho_{k-2} & \rho_{k-1} \\
\rho_{1} & 1 & \rho_{1} & \cdots & \rho_{k-3} & \rho_{k-2} \\
\vdots & \vdots & \vdots & \ddots & \vdots & \vdots \\
\rho_{k-1} & \rho_{k-2} & \rho_{k-3} & \cdots & \rho_{1} & 1
\end{array}\right|}
$$

\section{Stasioneritas}

Stasioneritas adalah asumsi umum yang digunakan dalam konteks runtun waktu. Ada 2 jenis stasioner, yaitu:

1. Stasioner lemah, yaitu jika rataan dan variansi dari proses tersebut konstan.

2. Stasioner kuat, yaitu jika fungsi distribusi kumulatif dari $\left(Z_{t_{1}}, Z_{t_{2}}, \cdots, Z_{t_{n}}\right)$ sama dengan fungsi distribusi kumulatif dari $\left(Z_{t_{1}-k}, Z_{t_{2}-k}, \cdots, Z_{t_{n}-k}\right)$.

\section{Proses White Noise}

Proses white noise adalah barisan peubah acak $\left\{a_{t}\right\}$ yang independen dan berdistribusi normal dengan rataan konstan $E\left(a_{t}\right)=0$ dan variansi konstan $\operatorname{Var}\left(a_{t}\right)=\sigma_{a}^{2}$. Proses white noise memiliki fungsi autokovariansi:

.dan fungsi autokorelasi:

$$
\operatorname{Cov}\left(a_{t}, a_{t-k}\right)= \begin{cases}\sigma_{a}^{2}, & k=0 \\ 0, & k \neq 0\end{cases}
$$

$$
\operatorname{Corr}\left(a_{t}, a_{t-k}\right)= \begin{cases}1, & k=0 \\ 0, & k \neq 0\end{cases}
$$




\section{E. Maximum Likelihood Estimator (MLE)}

Misalkan $X_{1}, X_{2}, \cdots, X_{n}$ adalah peubah acak dengan fungsi peluang masing-masing $f\left(x_{i}\right), i=$ $1,2, \cdots, n$. Maka langkah-langkah untuk menentukan penduga parameter dalam model dengan metode maximum likelihood adalah sebagai berikut:

1. Tentukan fungsi likelihood: $L(\theta)=f\left(x_{1}, x_{2}, \cdots, x_{n}\right)=\prod_{i=1}^{n} f\left(x_{i}\right)$.

2. Tentukan fungsi log-likelihood: $l=\ln (L(\theta))$.

3. Tentukan turunan pertama dari fungsi log-likelihood terhadap parameter $\theta$. Maka penyelesaian dari persamaan ini merupakan estimator maksimum likelihood untuk $\theta$.

\section{F. Proses Autoregressive}

Dalam model runtun waktu autoregressive $(A R)$, sebuah observasi $\left(Z_{t}\right)$ berkaitan langsung dengan observasi-observasi sebelumnya $\left(Z_{t-1}, Z_{t-2}, \cdots, Z_{t-p}\right)$. Bentuk umum suatu proses autoregressive dengan orde $p$ adalah:

$$
Z_{t}=\emptyset_{1} Z_{t-1}+\emptyset_{2} Z_{t-2}+\cdots+\emptyset_{p} Z_{t-p}+\varepsilon_{t}
$$

dimana $\varepsilon_{t} \sim N\left(0, \sigma_{t}^{2}\right)$ dan $\varepsilon_{t}$ tidak berkorelasi dengan $Z_{t-1}, \cdots, Z_{t-p}$. Grafik $A C F$ dari $A R(p)$ memiliki ciri-ciri menurun secara eksponensial menuju nol, sedangkan grafik $P A C F$ dari $A R(p)$ mengalami cut off setelah lag ke-p.

\section{G. Proses Moving Average}

Dalam model runtun waktu moving avegare (MA), nilai sekarang suatu proses dinyatakan sebagai jumlah tertimbang nilai galat saat ini dan masa lalu sampai $q$ satuan waktu ke belakang. Bentuk umum suatu proses moving average dengan orde $q$ adalah:

$$
Z_{t}=\varepsilon_{t}-\theta_{1} \varepsilon_{t-1}-\theta_{2} \varepsilon_{t-2}-\cdots-\theta_{p} \varepsilon_{t-q}
$$

dimana $\varepsilon_{t} \sim N\left(0, \sigma_{t}^{2}\right)$. Grafik $A C F$ dari $M A(q)$ memiliki ciri-ciri mengalami cut off setelah lag ke- $q$, sedangkan grafik $P A C F$ dari $M A(q)$ menurun secara eksponensial menuju nol.

\section{H. Proses Autoregressive Moving Average}

Proses autoregressive moving average (ARMA) adalah gabungan dari proses autoregressive dan proses moving average. Proses $\left\{Z_{t}\right\}$ dikatakan mengikuti proses ARMA $(p, q)$, jika memenuhi:

$$
Z_{t}=\emptyset_{1} Z_{t-1}+\cdots+\emptyset_{p} Z_{t-p}+\varepsilon_{t}-\theta_{1} \varepsilon_{t-1}-\cdots-\theta_{p} \varepsilon_{t-q}
$$

dimana $\varepsilon_{t}$ adalah proses white noise yang berdistribusi normal dengan rataan nol dan variansi $\sigma_{\varepsilon}^{2}$.

Rataan tak bersyarat dari proses $\operatorname{ARMA}(p, q)$ adalah sama dengan nol. Sedangkan rataan bersyarat dari proses $A R M A(p, q)$ adalah $\emptyset_{1} Z_{t-1}+\cdots+\emptyset_{p} Z_{t-p}-\theta_{1} \varepsilon_{t-1}-\cdots-\theta_{p} \varepsilon_{t-q}$. Dan variansi bersyaratnya sama dengan $\sigma_{\varepsilon}^{2}$. Plot $A C F$ dan $\operatorname{PACF} \operatorname{ARMA}(p, q)$ memiliki ciri-ciri menurun secara eksponensial menuju nol,

\section{Estimasi Model $\operatorname{ARMA}(0,1)$ atau $M A(1)$}

Model dari runtun waktu $\left\{Z_{t}\right\}$ yang mengikuti proses $M A(1)$ adalah sebagai berikut:

$$
Z_{t}=\varepsilon_{t}-\theta_{1} \varepsilon_{t-1}
$$

dimana $\varepsilon_{t}$ adalah proses white noise. Parameter dalam model MA(1) dapat diduga dengan menggunakan metode maximum likelihood. Di bawah asumsi normalitas dan dengan diberikan asumsi tambahan $\varepsilon_{0}=0$, fungsi likelihood dari proses $M A(1)$ adalah:

maka, fungsi log-likelihoodnya adalah:

$$
L=f\left(Z_{1}, \cdots, Z_{T} \mid \varepsilon_{0}=0 ; \boldsymbol{\theta}\right)=\prod_{t=1}^{T} \frac{1}{\sqrt{2 \pi \sigma_{\varepsilon}^{2}}} \exp \left(-\frac{\varepsilon_{t}^{2}}{2 \sigma_{\varepsilon}^{2}}\right)
$$

$$
l=\ln f\left(Z_{1}, \cdots, Z_{T} \mid \varepsilon_{0}=0 ; \boldsymbol{\theta}\right)=-\frac{T}{2} \ln (2 \pi)-\frac{T}{2} \ln \left(\sigma_{\varepsilon}^{2}\right)-\sum_{t=1}^{T} \frac{\varepsilon_{t}^{2}}{2 \sigma_{\varepsilon}^{2}}
$$


Selanjutnya untuk memperoleh penduga parameter $\theta$, dapat dicari nilai maksimum dari fungsi loglikelihood dengan menyelesaikan persamaan $\frac{\partial l}{\partial \theta}=0$.

\section{J. Runtun Waktu Tidak Stasioner}

Diperlukan suatu transformasi untuk mengubah data runtun waktu yang bersifat tidak stasioner menjadi stasioner, sehingga data tersebut dapat kemudian dimodelkan dengan model-model stasioner yang telah dijelaskan pada pembahasan sebelumnya. Transformasi yang dapat digunakan adalah transformasi diferensi, dengan rumus sebagai berikut:

$$
\nabla^{d} Z_{t}=(1-\mathrm{B})^{d} Z_{t}
$$

dimana $\nabla^{d} Z_{t}$ adalah selisih ke- $d$ untuk suatu runtun waktu $Z_{t}$ dan $B$ adalah operator backward shift.

\section{K. Uji Augmented Dickey Fuller (ADF)}

Uji $A D F$ atau uji akar unit digunakan untuk menguji kestasioneran data runtun waktu. Pengujian dilakukan dengan mengecek ada tidaknya akar unit dalam model runtun waktu, misal $Z_{t}=$ $\emptyset Z_{t-1}+\varepsilon_{t}$. Hipotesis pengujian yang digunakan adalah:

$H_{0}: \varnothing=1$ (data mengandung akar unit atau tidak stasioner)

$H_{1}: \varnothing \neq 1$ (data tidak mengandung akar unit atau stasioner)

dengan statistik uji:

$$
A D F=\frac{\widehat{\varnothing}}{S E(\widehat{\varnothing})}
$$

dan kriteria keputusan $H_{0}$ ditolak jika $p-$ value $<\alpha$ atau nilai statistik uji $A D F$ kurang dari tabel $A D F$.

\section{Uji ARCH-LM}

Uji ARCH-LM digunakan untuk menguji ada tidaknya heteroskedastisitas bersyarat atau efek $A R C H$ pada galat dari model runtun waktu. Misalkan $\varepsilon_{t}=Z_{t}-\mu_{t}$ adalah galat dari model rataan, maka barisan $\varepsilon_{t}^{2}$ digunakan untuk menguji keberadaan $A R C H$. Uji ini sama dengan uji statistik $F$ pada umumnya untuk menguji $\alpha_{i}=0(i=1, \cdots, m)$ dalam regresi linear:

$$
\varepsilon_{t}^{2}=\alpha_{0}+\alpha_{1} \varepsilon_{t-1}^{2}+\cdots+\alpha_{m} \varepsilon_{t-m}^{2}+a_{t} \text { dimana } t=m+1, \cdots, T
$$

Hipotesis pengujian yang digunakan adalah:

$H_{0}: \alpha_{1}=\alpha_{1}=\cdots=\alpha_{1}=0$ (tidak terdapat efek ARCH)

$H_{1}: \exists \alpha_{i} \neq 0, i=1,2, \cdots, m$ (terdapat efek $A R C H$ )

dengan statistik uji:

$$
F=\frac{(J K T-J K G) / m}{J K G /(T-2 m-1)}
$$

dimana $J K T=\sum_{t=m+1}^{T}\left(\varepsilon_{t}^{2}-\bar{\omega}\right)^{2}$ dengan $\bar{\omega}$ rataan sampel dari $\varepsilon_{t}^{2}$, dan $J K G=\sum_{t=m+1}^{T} \hat{a}_{t}^{2}$ dengan $\hat{a}_{t}$ adalah galat kuadrat terkecil.

\section{Akaike Information Criterion (AIC)}

Akaike Information Criterion adalah kriteria pemilihan model sebagai perluasan dari prinsip maximum likelihood. Nilai AIC didefinisikan dengan rumus:

$$
A I C=-2(\text { loglikelihood })+2 N
$$

dimana loglikelihood adalah fungsi log likelihood dari estimasi parameter dan $N$ adalah jumlah observasi. Model yang dipilih adalah model dengan nilai AIC terendah. 


\section{Pembahasan}

\section{A. $\quad A R C H(m)$}

Model autoregressive conditional heteroscedasticity menginterpretasikan bahwa variansi dari $Z_{t}$ dipengaruhi oleh galat kuadrat pada periode yang lalu. Model $A R C H(m)$ didefinisikan sebagai berikut:

$$
\varepsilon_{t}=a_{t} \sqrt{\alpha_{0}+\alpha_{1} \varepsilon_{t-1}^{2}+\cdots+\alpha_{m} \varepsilon_{t-m}^{2}}
$$

dimana $\alpha_{0}$ adalah kostanta dan $\alpha_{i}$ adalah parameter yang tidak diketahui dengan $i=1,2, \cdots, m$, yang memenuhi syarat $\alpha_{0}>0$ dan $\alpha_{i} \geq 0$.

Rataan bersyarat dari proses $A R C H(m)$ bernilai nol, maka rataan tak bersyarat dari $A R C H(m)$ juga bernilai nol. Variansi bersyarat dari $A R C H(m)$ adalah $\alpha_{0}+\alpha_{1} \varepsilon_{t-1}^{2}+\cdots+\alpha_{m} \varepsilon_{t-m}^{2}$, sedangkan variansi tak bersyarat dari $A R C H(m)$ adalah $\frac{\alpha_{0}}{1-\alpha_{1}-\cdots-\alpha_{m}}$. Fungsi autokovariansi antara $\varepsilon_{t}$ dan $\varepsilon_{t-k}$ pada $A R C H(m)$ adalah nol untuk $k \geq 1$.

Teorema 3.3.1. Untuk bilangan bulat $r$, momen ke- $2 r$ dari proses $\mathrm{ARCH}(1)$ dengan $\alpha_{0}>0$, dan $\alpha_{1} \geq$ 0 ada, jika dan hanya jika:

$$
\alpha_{1}^{r} \prod_{j=1}^{r}(2 j-1)<1
$$

Teorema 3.4.1. Proses $A R C H(m)$ dengan $\alpha_{0}>0$, dan $\alpha_{1}, \alpha_{2}, \cdots \alpha_{m} \geq 0$, adalah kovariansi yang stasioner jika dan hanya jika persamaan karakteristik yang terkait memiliki akar-akar di luar lingkaran satuan. Dimana variansi stasioner diberikan sebagai berikut:

$$
E\left(\varepsilon_{t}^{2}\right)=\frac{\alpha_{0}}{1-\sum_{j=1}^{m} \alpha_{j}} .
$$

Parameter $\alpha_{0}, \alpha_{1}, \cdots, \alpha_{m}$ dalam model $A R C H(m)$ dapat diduga dengan metode maximum likelihood. Di bawah asumsi normalitas, fungsi likelihood dari model $A R C H(m)$ adalah:

$$
f\left(\varepsilon_{1}, \cdots, \varepsilon_{T} ; \boldsymbol{\alpha}\right)=f\left(\varepsilon_{1}, \cdots, \varepsilon_{m} ; \boldsymbol{\alpha}\right) \times \prod_{t=m+1}^{T} \frac{1}{\sqrt{2 \pi h_{t}^{2}}} \exp \left[-\frac{\varepsilon_{t}^{2}}{2 h_{t}^{2}}\right]
$$

karena bentuk dari $f\left(\varepsilon_{1}, \cdots, \varepsilon_{m} ; \boldsymbol{\alpha}\right)$ sangat rumit, bentuk ini biasanya dihilangkan dari fungsi likelihood, maka fungsi likelihood dari model $\mathrm{ARCH}(\mathrm{m})$ menjadi:

$$
f\left(\varepsilon_{m+1}, \cdots, \varepsilon_{T} \mid \cdots, \varepsilon_{m} ; \boldsymbol{\alpha}\right)=\prod_{t=m+1}^{T} \frac{1}{\sqrt{2 \pi h_{t}^{2}}} \exp \left[-\frac{\varepsilon_{t}^{2}}{2 h_{t}^{2}}\right]
$$

sebagai akibatnya, fungsi log-likelihood dari model $A R C H(m)$ adalah:

$$
l\left(\varepsilon_{m+1}, \cdots, \varepsilon_{T} \mid \cdots, \varepsilon_{m} ; \boldsymbol{\alpha}\right)=-\sum_{t=m+1}^{T}\left[\frac{1}{2} \ln \left(h_{t}^{2}\right)+\frac{1}{2} \frac{\varepsilon_{t}^{2}}{h_{t}^{2}}\right]
$$

dimana $h_{t}^{2}=\alpha_{0}+\alpha_{1} \varepsilon_{t-1}^{2}+\cdots+\alpha_{m} \varepsilon_{t-m}^{2}$. Selanjutnya, untuk memperoleh penduga parameter $\alpha_{0}, \alpha_{1}, \cdots, \alpha_{m}$ dapat dicari nilai maksimum dari fungsi log-likelihood dengan menyelesaikan persamaan $\frac{\partial l}{\partial \alpha_{0}}=0, \frac{\partial l}{\partial \alpha_{2}}=0, \cdots, \frac{\partial l}{\partial \alpha_{m}}=0$.

Untuk menentukan orde $m$ dalam model $A R C H(m)$ digunakan $P A C F$ dari runtun $\varepsilon_{t}^{2}$, dengan melihat lag PACF yang signifikan.

\section{B. Analisis Data Tingkat Inflasi Indonesia}

Data terdiri atas 155 observasi bulanan dari tingkat inflasi Indonesia selama periode Januari 2003 sampai dengan Nopember 2015. Tabel di bawah ini memberikan gambaran statistik dari data yang akan digunakan. 
Statistik Deskriptif Data Awal

\begin{tabular}{|c|c|c|c|c|c|c|}
\hline & Mean & Median & Maximum & Minimum & Kurtosis & Prob. ADF \\
\hline Nilai & 7,16 & 6,51 & 18,38 & 2,41 & 5,68 & 0,1576 \\
\hline
\end{tabular}

Hasil dari uji Augmented Dickey Fuller (ADF) dalam Tabel 3.1 menunjukkan bahwa data memiliki unit root yang berarti data tidak stasioner. Untuk memperoleh data yang stasioner, dilakukan transformasi diferensi pertama pada data, dengan rumus $R_{t}=Z_{t}-Z_{t-1}$, dimana $R_{t}$ adalah data baru hasil transformasi yang disbeut dengan data return.

\section{Statistik Deskriptif Data Return}

\begin{tabular}{|c|c|c|c|c|c|c|}
\hline & Mean & Median & Maximum & Minimum & Kurtosis & Prob. ADF \\
\hline Nilai & $-0,0246$ & $-0,07$ & 8,83 & $-8,26$ & 34,41 & 0,01 \\
\hline
\end{tabular}

Nilai probabilitas dari uji $A D F$ yang kurang dari $\alpha=0,05$, menunjukkan bahwa data tidak mengandung unit root, sehingga dapat disimpulkan bahwa hasil transformasi diferensi pertama sudah menghasilkan proses stasioner pada data. Jadi, data yang akan digunakan untuk pembentukan model adalah data return. Plot $A C F$ dan $P A C F$ dari data return diberikan pada gambar di bawah ini.

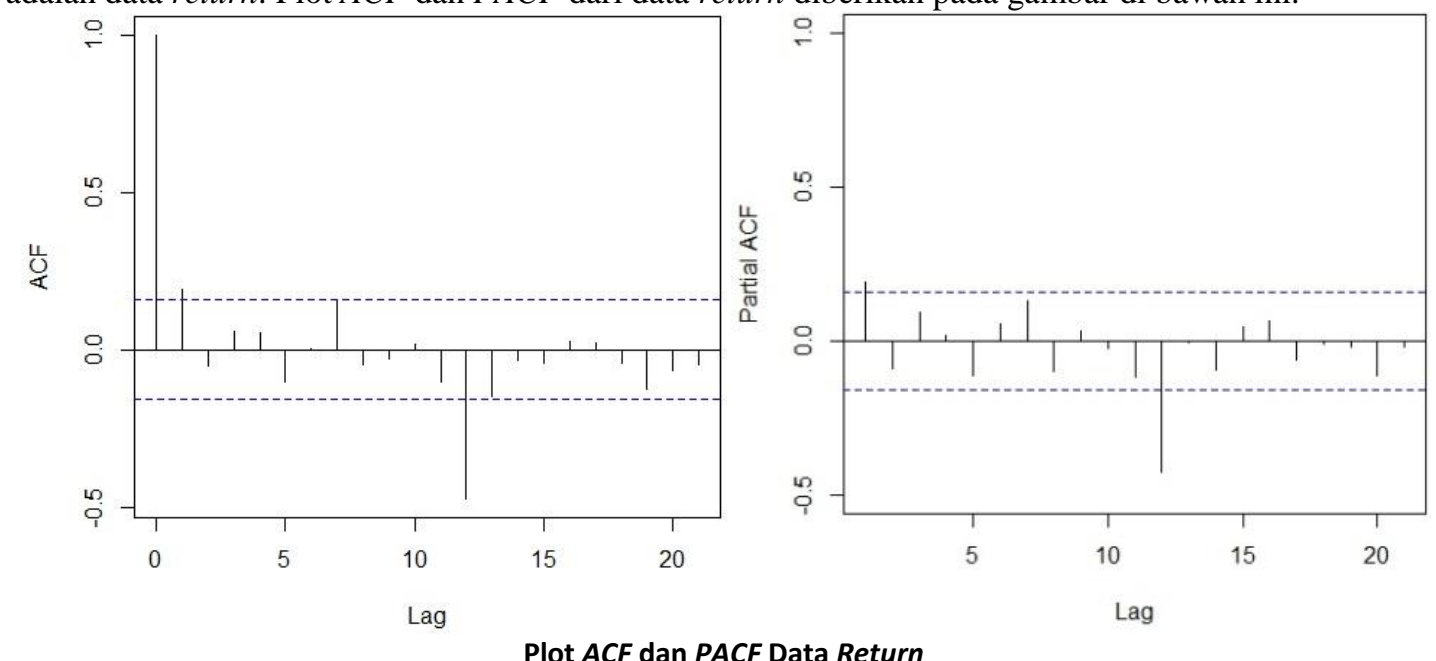

Plot $A C F$ dan PACF mengalami cut off setelah lag ke-1. Maka model yang sesuai dengan lag ke-1 adalah $A R(1), M A(1), A R M A(1,1)$. Selanjutnya, untuk memperoleh model terbaik, digunakan kriteria pemilihan model Akaike Information Criteria (AIC).

\begin{tabular}{|c|c|c|c|}
\hline Model & $A R(1)$ & $M A(1)$ & $A R M A(1,1)$ \\
\hline$A I C$ & 493,19 & 492,05 & 493,51 \\
\hline
\end{tabular}

Maka model rataan terbaik untuk data return adalah model $M A(1)$, karena memiliki nilai $A I C$ terendah. Estimasi model $M A(1)$ yang diperoleh adalah $R_{t}=-0,028+\varepsilon_{t}-0,231 \varepsilon_{t-1}$.

Uji $A R C H-L M$ pada runtun galat $M A(1)$ menghasilkan $p$-value $=0,001<0,05$ yang berarti tolak $H_{0}$, maka dapat disimpulkan bahwa terdapat efek $A R C H$ pada galat. Selanjutnya, untuk menetukan orde $A R C H$ dapat digunakan $P A C F$ dari galat kuadrat $\left(\varepsilon_{t}^{2}\right)$. 


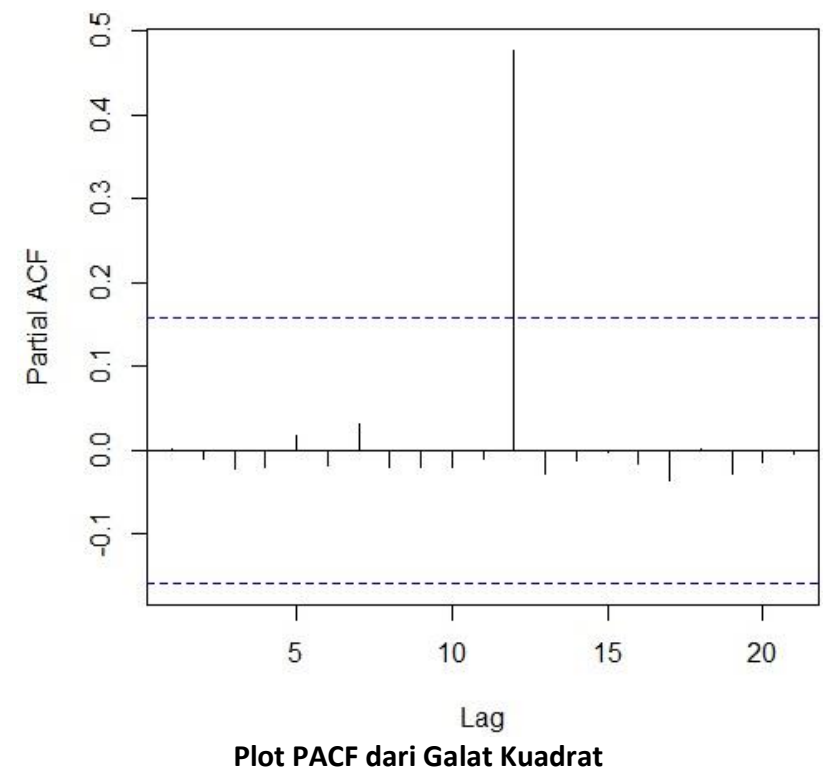

Plot PACF dari galat kuadrat melewati garis signifikan pada lag 12, maka orde $A R C H$ untuk galat dalam mode $M A(1)$ adalah $A R C H(12)$, dengan estimasi model sebagai berikut:

$$
\varepsilon_{t}=a_{t} \sqrt{0,5597+0,1783 \varepsilon_{t-7}^{2}+0,11557 \varepsilon_{t-12}^{2}}
$$

Dengan melakukan uji $A R C H-L M$ pada runtun galat dari model $A R C H(12)$, diperoleh nilai $p-$ value $=0,998<0,05$, maka dapat disimpulkan bahwa sudah tidak terdapat efek $A R C H$ dalam galat model $A R C H(12)$.

\section{Penutup}

\section{A. Kesimpulan}

1. Runtun waktu heteroskedastisitas tidak dapat hanya dimodelkan dengan model ARIMA biasa. Model yang dapat mengakomodasikan runtun waktu yang bersifat heteroskedastisitas adalah model $A R C H$. Model $A R C H(m)$ adalah sebagai berikut:

$$
\varepsilon_{t}=a_{t} \sqrt{h_{t}}, \quad h_{t}=h_{t}+\sum_{i=1}^{m} \alpha_{i} \varepsilon_{t-1}^{2}
$$

2. Model $A R C H$ dapat diterapkan pada data inflasi Indonesia periode Januari 2003 sampai dengan Nopember 2015, karena data bersifat heteroskedastisitas bersyarat. Dari analisis yang dilakukan terhadap data tersebut, dapat disimpulkan bahwa data return inflasi Indonesia memiliki model rataan $M A(1)$ sebagai berikut:

dengan galat mengikuti proses $A R C H(12)$ :

$$
R_{t}=-0,028+\varepsilon_{t}-0,231 \varepsilon_{t-1}
$$

dimana $a_{t} \sim W N(0,1)$, dan model volatilitasnya:

$$
\varepsilon_{t}=a_{t} h_{t}^{1 / 2}
$$

$$
h_{t}=0,5597+0,1783 \varepsilon_{t-7}^{2}+0,1157 \varepsilon_{t-12}^{2}
$$

\section{B. Saran}

Disarankan untuk penelitian selanjutnya membahas tentang model-model perluasan ARCH, sehingga dapat memperoleh informasi yang lebih lengkap dalam menganalisis data finansial. 


\section{Daftar Pustaka}

Anton, Howard dan Chris Rorres. 2000. Elementary Linear Algebra. Edisi ke-8. New York: John Wiley \& sons, Inc.

Bera, Anil K, M.L. Higgins. 1993. ARCH Models: Properties, Estimation and Testing. Journal of Economics Surveys Vol.7 No.4.

Bozdogan, Hamparsum. 2000. Akaike's Information Criterion and Recent Developments in Information Complexity. Journal of Mathemathical Psychology vol 44 page 62-91.

Engle, R.F. 1982. Autoregressive Conditional Heteroscedasticity with Estimates of The Variance of United Kingdom Inflation. Journal of Econometrica vol 50 No.4 page 987-1007.

Granger, C.W.J., dan A. Anderson. 1978. An Introduction to Bilinear Time-Series Models. Gottingen: Vandenhoeck and Ruprecht.

Lo, Michael S. 2003. Generalized Autoregressive Conditional Heteroscedasticity Time Series Models. Thesis. Burnaby: Department of Statistics and Actuarial Science, Simon Fraser University.

Makridakis. 1999. Metode dan Aplikasi Peramalan. Edisi 2. Jakarta: Binarupa Aksara.

Purcell, E.J., D. Varberg dan Steven E.R. 2003. Kalkulus. Edisi 8, jilid 2. Jakarta: Erlangga.

Purnomo, Kurtanto. 2010. Estimasi Underground Economy Periode 2000-2009 Melalui Pendekatan Moneter. Universitas Terbuka.

Soejoeti, Zanzawi. 1987. Analisis Runtun Waktu. Jakarta: Karunia Jakarta Universitas Terbuka.

Tsay, R.S. 2002. Analysis of Financial Time Series. New York: John Wiley \& sons, Inc.

Walpole, R.E. dan Raymond H.M. 1995. Ilmu Peluang dan Statistika untuk Insinyur dan Ilmuwan. Edisi ke-4. Bandung: ITB.

Wei, William W.S. 2006. Time Series Analysis: Univariate and Multivariate Methods. Edisi ke-2. New York: Pearson Education, Inc. 